Supporting Information

\title{
Visible-Light-Active Plasmonic Ag-SrTiO 3 Nanocomposites for the Degradation of NO in Air with High Selectivity
}

\author{
Qian Zhang, ${ }^{\dagger}$ Yu Huang, ${ }^{*},+$ LifengXu, ${ }^{\dagger}$ Jun-ji Cao, $,{ }^{*},+\star$ Wingkei Ho, ${ }^{\S}$ \\ and Shun Cheng Lee" \\ ${ }^{\dagger}$ Key Laboratory of Aerosol Chemistry and Physics, Institute of Earth Environment, \\ Chinese Academy of Sciences, Xi'an 710061, China \\ ${ }^{\ddagger}$ State Key Lab of Loess and Quaternary Geology (SKLLQG), Institute of Earth \\ Environment, Chinese Academy of Sciences, Xi'an 710061, China \\ ${ }^{\S}$ Department of Science and Environmental Studies, The Hong Kong Institute of \\ Education, Hong Kong, China \\ "Department of Civil and Environmental Engineering, The Hong Kong Polytechnic \\ University, Hong Kong, China
}

Submitted to ACS Applied Materials \& Interfaces

*Corresponding author:

Prof. Yu Huang, E-mail address: huangyu@ieecas.cn

Prof. Jun-ji Cao, E-mail address: cao@ loess.llqg.ac.cn 


\section{SEM}
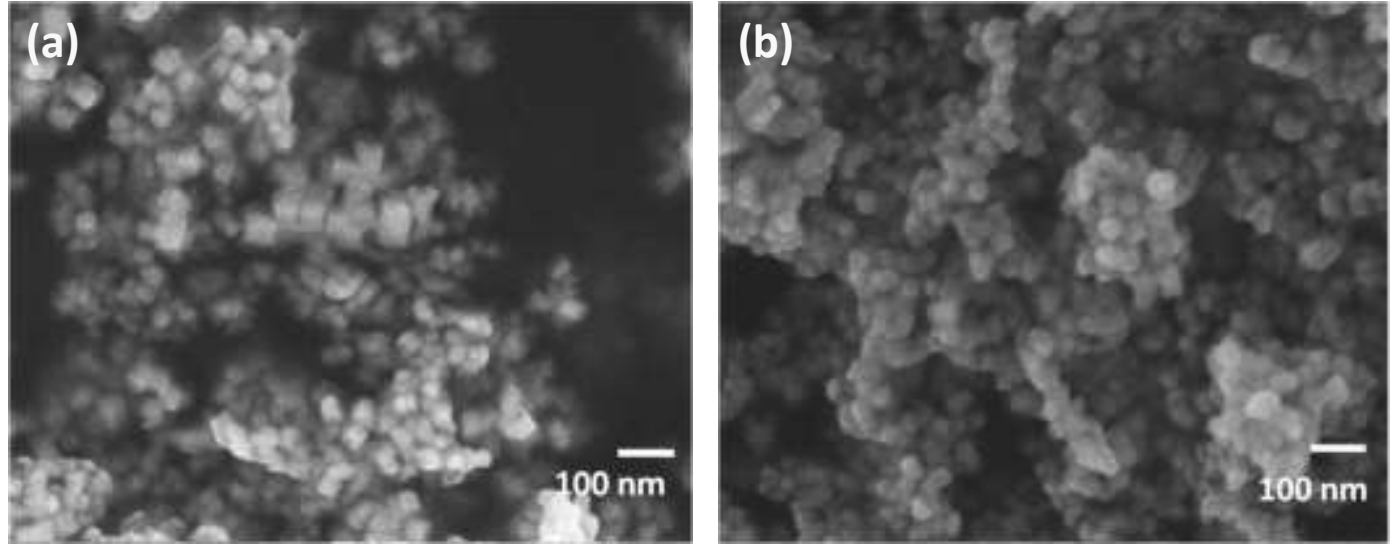

Figure S1. SEM images of pristine STO (a) and 0.5\% Ag-STO nanocomposites (b)

2. Growth mechanism of Ag-STO nanocomposites

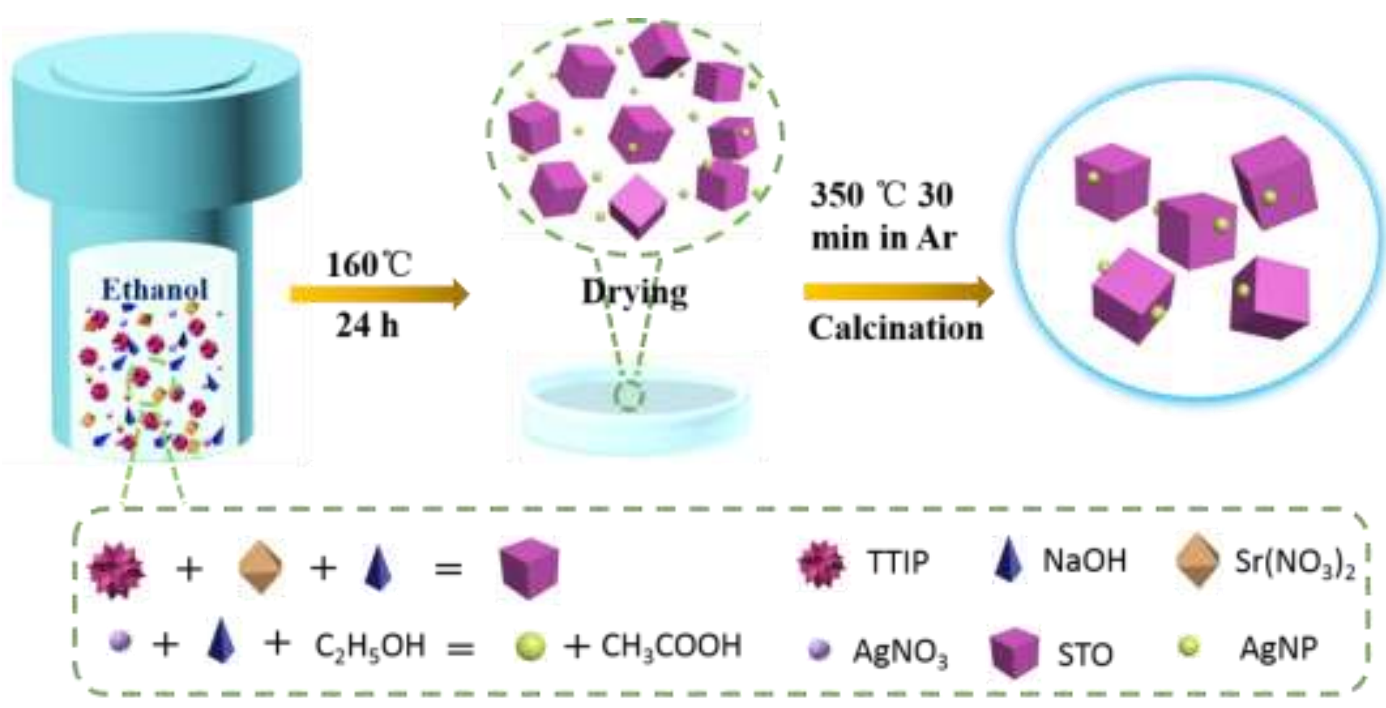

Scheme S1. Growth mechanism of Ag-STO nanocomposites in the one-pot

solvothermal process

\section{BET results}

Table S1. BET surface area of different photocatalysts

\begin{tabular}{cccccc}
\hline Sample & \multicolumn{2}{c}{ STO } & \multicolumn{2}{c}{ Ag-STO } & P25 \\
\hline Treatment & $\begin{array}{c}\text { Before Ar } \\
\text { annnealing }\end{array}$ & $\begin{array}{c}\text { After Ar } \\
\text { annnealing }\end{array}$ & $\begin{array}{c}\text { Before Ar } \\
\text { calcination }\end{array}$ & $\begin{array}{c}\text { After Ar } \\
\text { calcination }\end{array}$ & $/$ \\
\cline { 2 - 6 } $\begin{array}{c}\text { Surface } \\
\text { area } \\
\left(\mathrm{m}^{2} / \mathrm{g}\right)\end{array}$ & 60.16 & 59.96 & 60.10 & 48.34 & 55 \\
\hline
\end{tabular}




\section{Mott-Schottky plot}

The Mott-Schottky plot of STO were measured using a Parstat 4000 potentiostat in a conventional three-electrode cell, in which a platinum plate and $\mathrm{Ag} / \mathrm{AgCl} / \mathrm{saturated} \mathrm{KCl}$ electrode were used as counter and reference electrodes, respectively. $0.1 \mathrm{M} \mathrm{Na}_{2} \mathrm{SO}_{4}$ solution was served as the electrolyte. In order to fabricate the working electrode, ethyl cellulose and terpineol were first added into STO-ethanol solution to obtain a homogeneous suspension through the bath sonication. Then, the STO film were deposited onto the fluorine doped tin oxide (FTO) glass by dip coating for several times and dried at room temperature. The final composition of STO film was $0.18 \mathrm{wt} \%$ STO, $0.09 \mathrm{wt} \%$ ethyl cellulose, and $0.73 \mathrm{wt} \%$ terpineol. Afterwards, the STO electrodes were annealed in air at $500^{\circ} \mathrm{Cfor} 30 \mathrm{~min}$ to remove the additives and ensure the close electric contact with the substrate.

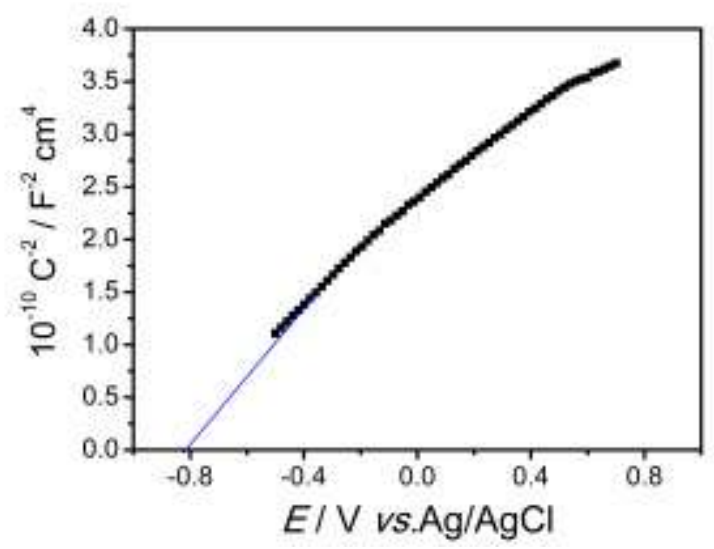

Figure S2. Mott-Schottky plot of STO in $0.1 \mathrm{M} \mathrm{Na}_{2} \mathrm{SO}_{4}$ solution (pH 7). Potential range: $-0.5 \sim 0.7 \mathrm{~V}$ vs. $\mathrm{Ag} / \mathrm{AgCl}$; frequency: $1000 \mathrm{~Hz}$; perturbation bias: $5 \mathrm{mV}$ 


\section{ESR spectra}
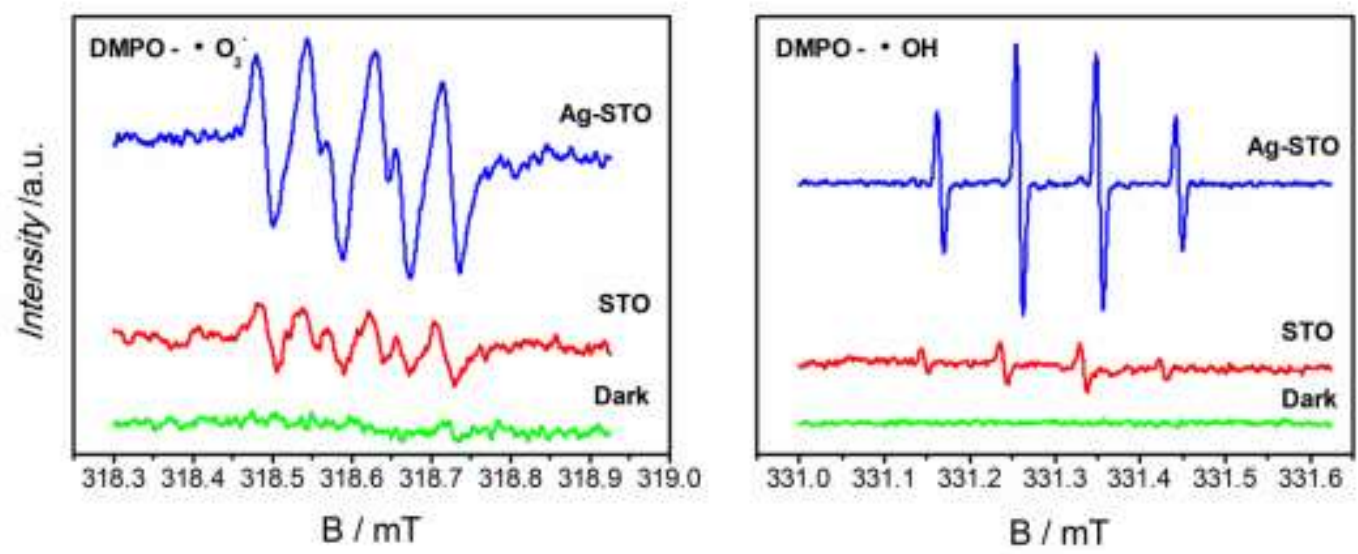

Figure S3. DMPO spin-trapping ESR spectra of STO and the $0.5 \% \mathrm{Ag}-\mathrm{STO}$ nanocomposite at UV wavelength of $280 \mathrm{~nm}$, with light on for $10 \mathrm{~min}$

\section{FT-IR spectra}

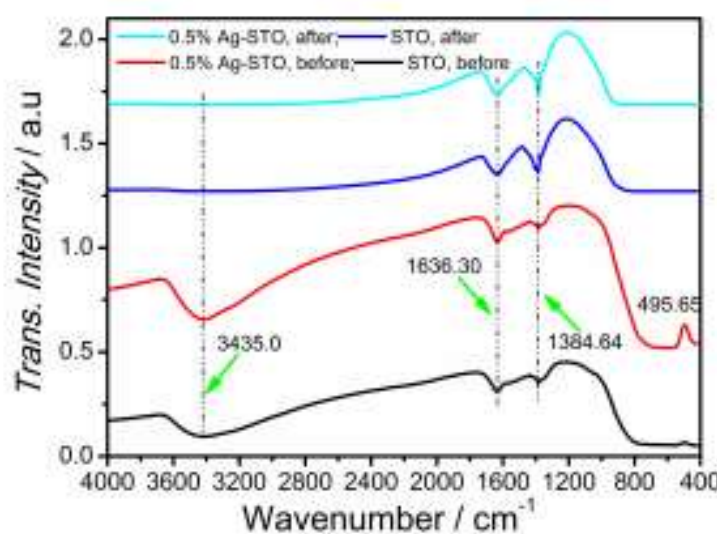

Figure S4. FT-IR spectra of pristine STO and 0.5\% Ag-STO nanocomposite, before and after reaction, respectively 